\title{
Mechanically induced phase transformations of the sigma phase of nanograined and of coarse-grained near-equiatomic $\mathrm{FeCr}$ alloys
}

\author{
B.F.O. Costa ${ }^{\text {a,* }}$, G. Le Caër ${ }^{b}$, J.M. Loureiro $^{\text {a }}$, V.S. Amaral ${ }^{\text {c }}$ \\ a Departamento de Física, Universidade de Coimbra, P-3004-516 Coimbra, Portugal \\ ${ }^{\mathrm{b}}$ GMCM UMR CNRS 6626, Université de Rennes I, Campus de Beaulieu, Bat. 11A, F-35042 Rennes Cedex, France \\ c Departamento de Fisica and CICECO, Universidade de Aveiro, P-3810-193 Aveiro, Portugal \\ Received 24 October 2005; received in revised form 15 December 2005; accepted 17 December 2005 \\ Available online 2 February 2006
}

\begin{abstract}
A coarse-grained tetragonal sigma phase $\sigma-\mathrm{Fe}_{0.54} \mathrm{Cr}_{0.46}$, prepared from an as-cast alloy, and a nanocrystalline $\sigma$ - $\mathrm{Fe}_{0.52} \mathrm{Cr}_{0.48} \mathrm{phase}$ were ballmilled in argon in a Fritsch P0 ball-mill at different vibration amplitudes. X-ray diffraction evidences solely a gradual transformation of the sigma phases into bcc phases. Room-temperature Mössbauer spectroscopy shows further the presence of a non-magnetic phase which remains non-magnetic at least down to $35 \mathrm{~K}$. It is attributed to an amorphous phase whose formation is favoured at grain boundaries by oxygen in such milling conditions. Possible explanations of the different final structures reported in the literature in high-energy ball-milled near-equiatomic Fe-Cr alloys are discussed.
\end{abstract}

(C) 2006 Elsevier B.V. All rights reserved.

Keywords: Fe-Cr; Sigma phase; Ball-milling; Amorphization; Mössbauer spectroscopy

\section{Introduction}

Near-equiatomic binary $\mathrm{Fe}-\mathrm{Cr}$ alloys and the multinary alloys derived from them are technologically important materials whose high-temperature corrosion and mechanical resistance are used in various industries, for instance in oil refineries or power plants to name just a few. At the elevated temperatures at which they are frequently in service, these alloys are however not stable. Two phenomena may occur according to the temperature of use: (a) a phase separation into two bcc phases, namely a Cr-rich $\alpha^{\prime}$ phase and a Fe-rich $\alpha$ phase [1] or (b) a precipitation of a sigma $\mathrm{Fe}-\mathrm{Cr}$ phase $[2,3]$. Both phenomena lead to a deterioration of the mechanical properties of these materials. The precipitation of a small fraction of the $\sigma$-phase makes the steel very brittle. The Fe-Cr system is further an archetypal system for the study of phase separation, more particularly by the mechanism of spinodal decomposition, as the lattice mismatch between bcc phases of $\mathrm{Fe}$ and $\mathrm{Cr}$ is quite small, with a relative lattice parameter variation $\left(a_{\mathrm{Cr}}-a_{\mathrm{Fe}}\right) / a_{\mathrm{Fe}} \approx 0.008[1,4-7]$.

\footnotetext{
* Corresponding author. Tel.: +351 239410630; fax: +351 239829158.

E-mail address: benilde@ci.uc.pt (B.F.O. Costa).
}

For similar reasons, the $\mathrm{Fe}-\mathrm{Cr}$ binary system is of interest to investigate the phase transformations which occur when the alloys become nanostructured. Nanostructured materials (grain size $<100 \mathrm{~nm}$ ) are indeed characterized by a rather large volume fraction of grain boundaries which steadily increases when the grain size $d$ decreases. Further their typical grain size is often of the order of or smaller than the characteristic lengths of many basic physical mechanisms. Various properties of such materials are then expected to change as compared to those of their coarsegrained counterparts when $d$ becomes lower than some typical size.

Phase transformations in nanocrystalline materials may differ indeed from those of classical materials (transformation kinetics, metastable phases, ...). Differences were reported for instance for $\mathrm{Fe}-\mathrm{Cr}$ and $\mathrm{Fe}-\mathrm{Cr}-\mathrm{Sn}$ alloys $[10,11]$ and for nearly equiatomic $\mathrm{Fe}-\mathrm{V}$ alloys for which the formation of a metastable B2 alloy competes with that of a sigma phase $[8,9]$. Phase transformations driven by plastic deformation (ball-milling, severe plastic deformation, cold-rolling, etc.) are both of fundamental and of applied interest [10-19]. Magnetic measurements and Mössbauer spectra reveal for instance that nanostructured $\mathrm{Fe}_{0.30} \mathrm{Cr}_{0.70}$ prepared from mechanical alloying of mixtures of elemental powders [19a] or from high-energy 
milling of powdered as-cast alloys [19b] are heterogeneous in their dynamical state of equilibrium. Indeed, intragranular composition fluctuations of $\sim 0.1$ in amplitude on a scale of a few nanometers were evidenced because of the particular magnetic properties of the investigated alloys.

However, in some cases, extrinsic factors, for instance in high-energy ball-milling a contamination by residual gases or by milling materials, may drive the transformation to a final state which differs from the one which would be reached by the sole action of shearing. Indeed, iron and near-equiatomic $\mathrm{Fe}-\mathrm{Cr}$ alloys were shown to be sensitive to the presence of gases when ground in high-energy ball-mills [20-29]. Rawers et al. [20-22] compared the microstructures of $\alpha$-Fe ground in argon and in nitrogen in a Szegvari type attrition mill. They concluded that the majority of mechanically infused nitrogen atoms are either associated with the grain boundary regions or concentrated in crystalline nanoclusters along grain boundaries. Milling $\mathrm{Fe}$ in a continuous flow of nitrogen produces even iron nitrides with significantly higher nitrogen contents (up to $\mathrm{Fe}_{2} \mathrm{~N}$ ) [27].

Shen et al. [26] observed, by Mössbauer spectroscopy, that concentrated bcc- $\mathrm{Fe}_{0.60} \mathrm{Cr}_{0.40}$ alloys ground in vacuum $\left(6 \times 10^{-2} \mathrm{~Pa}\right)$ remain ferromagnetic at room temperature while they become essentially paramagnetic when ground during $85 \mathrm{~h}$ in argon. As qualitatively similar results were obtained by Fnidiki et al. [24,25] for a series of mechanically alloyed $\mathrm{Fe}-\mathrm{Cr}$ alloys, Shen et al. concluded to the existence of a very 'disordered' $\mathrm{Fe}-\mathrm{Cr}+\mathrm{O}+\mathrm{N}$ grain boundary structure [26]. By contrast, a nanocrystalline ferromagnetic bcc- $\mathrm{Fe}_{0.50} \mathrm{Cr}_{0.50}$ was obtained by Koyano et al. [28] by high-energy ball-milling of elemental powder mixtures during $200 \mathrm{~h}$ in argon.

It would thus be desirable to clarify the origins of such different final structures and the eventual connection between the poorly defined 'disordered' structure and the amorphous phases reported to form in bcc- $\mathrm{Fe}_{1-x} \mathrm{Cr}_{x}$ alloys either by grinding for $x=0.72$ [29] or by thermal coevaporation for $0.25<x<0.6$ [30]. For that purpose, more must be known about the specific roles of oxygen and nitrogen as amorphous $\mathrm{Fe}-\mathrm{Cr}$ phases are observed too in conditions in which residual gases play no significant role $[29,31]$. A recent study of phase transformations occurring during long-time annealing in $\mathrm{Fe}-\mathrm{Cr}$ films showed for instance that an amorphous phase is formed along with the crystalline phases expected for Cr-rich alloys [31].

The behaviour under milling in vacuum $\left(10^{-6} \mathrm{~Pa}\right)$ of a sigma $\mathrm{Fe}-\mathrm{Cr}$ phase was studied earlier by Bakker et al. [13,32,33]. They concluded that the sigma phase is not stable and that it transforms into a bcc nanostructured phase which is the sole phase identified from X-ray diffraction patterns for more than $10 \mathrm{~h}$ of milling. As milling is performed in vacuum, the bcc phase, once formed from the sigma phase with its stationary grain size ( $d=7 \mathrm{~nm}$ [13]), is not expected to evolve during prolonged milling as seen by Shen et al. [26]. However, this interpretation does not satisfactorily account for the reported variation of the low-temperature magnetization with milling time. The magnetization at $4.2 \mathrm{~K}$ reaches a maximum of about $1.7 \mu_{\mathrm{B}} / \mathrm{at}$ Fe after $10 \mathrm{~h}$ of milling and then decreases down to $1.2 \mu_{\mathrm{B}} / \mathrm{at} \mathrm{Fe}$ after $100 \mathrm{~h}$ milling. The magnetization expected for a coarse-grained bcc Fe-Cr alloy with the same composition $[34,35]$ is about $2 \mu_{\mathrm{B}} /$ at Fe. This mag- netization difference of about $40 \%$ seems difficult to explain by the effect on magnetic properties of further decrease of the bcc grain size into the nanometer range as assumed in [13]. For instance the magnetization of alpha iron at $5 \mathrm{~K}$ was found to be smaller by $10-20 \%$ than that of ball-milled $n-F e(d=20-30 \mathrm{~nm})$ contaminated by 2 at\% $\mathrm{Cr}$ [36]. We notice that grain boundary magnetic disorder effects were observed at low temperature in ball-milled n-Fe and in n-Fe thin films [36,37].

The average room-temperature hyperfine magnetic field at ${ }^{57} \mathrm{Fe}$ nuclei of nanocrystalline $\alpha-\mathrm{Fe}$ is close to that of coarsegrained $\alpha-\mathrm{Fe}$, being reduced by at most $5 \%$, once the unavoidable effects of contamination are properly taken into account [38-41]. Similarly, the mean hyperfine magnetic fields of coarse-grained bcc $\mathrm{Fe}_{0.51} \mathrm{Cr}_{0.49}$ are essentially identical $(\langle B\rangle=16 \mathrm{~T})$ when the alloy is filed $(d=250 \mathrm{~nm})$ or when it is ball-milled $(d=25 \mathrm{~nm})$ despite domain sizes $d$ which differ by an order of magnitude [42].

To summarize, the evolution of near-equiatomic $\mathrm{Fe}-\mathrm{Cr}$ alloys, either bcc or sigma, during high-energy ball-milling in argon or in vacuum, is puzzling and not fully understood. The aim of the present paper is to investigate the stability of a sigmaFeCr intermetallic compound under high-energy ball-milling in argon, using Mössbauer spectroscopy as the main characterization technique of the structural changes. A final aim is to present reasonable arguments to account for the different structures reported to form by high-energy ball-milling of concentrated $\mathrm{Fe}-\mathrm{Cr}$ alloys.

\section{Experimental details}

Three series of sigma FeCr intermetallic compounds were ball-milled in a Fritsch P0 mill. The first two series correspond to the milling of a coarse-grained $\mathrm{Fe}_{0.54} \mathrm{Cr}_{0.46}$ alloy prepared by melting together in argon atmosphere appropriate amounts of $\mathrm{Fe}$ ( $>99.9 \%$ purity) and $\mathrm{Cr}$ ( $99.995 \%$ purity) in an induction furnace. The alloy was melted three times to ensure homogeneization. The composition, near the center of the $\sigma$ phase domain, is close to that studied by Bakker et al. $[13,32,33]$. The as-cast alloy consists then in a bcc phase. The sigma phase was formed by annealing the as-cast alloy in vacuum at $700{ }^{\circ} \mathrm{C}$ for $100 \mathrm{~h}$. Then the formed $\sigma$-phase intermetallic compound was powdered with a pestle in an agate mortar into particles of about $90 \mu \mathrm{m}$. A mass of $5 \mathrm{~g}$ of $\sigma$-FeCr was then ballmilled in accumulated milling times under argon atmosphere. Ball-milling was carried out in a Fritsch P0 mill with a hardened steel vial and a hardened steel ball whose diameter is $5 \mathrm{~cm}$ and whose mass is $500 \mathrm{~g}$. The vial cover was home made to permit an easy filling of the vial with argon ( $99.9990 \%$ pure). The argon atmosphere was introduced in the vial every $100 \mathrm{~min}$ of milling. The mill was working at an amplitude of vibration $A$ of about 2.5 for the first series of samples and at its maximum amplitude ( $A$ about 3 in scale) for the second series. The third series of samples corresponds to a nanocrystalline $\mathrm{Fe}_{0.515} \mathrm{Cr}_{0.485}$ sigma phase and was ball-milled at the maximum amplitude $(A=3)$. For the sake of simplicity, the three previous series will be denoted hereafter as $S_{\mathrm{cg} 1}\left(\mathrm{Fe}_{0.54} \mathrm{Cr}_{0.46}\right.$, $A=2.5), S_{\mathrm{cg} 2}\left(\mathrm{Fe}_{0.54} \mathrm{Cr}_{0.46}, A=3\right)$ and $S_{\mathrm{nc}}\left(\mathrm{Fe}_{0.515} \mathrm{Cr}_{0.485}, \mathrm{n}-\sigma\right.$ phase $)$, respectively. A sample of a given series $S_{x}$ milled for a time $t_{\mathrm{m}}$ will be further denoted as $S_{x}\left(t_{\mathrm{m}}\right)$.

The nanocrystalline bcc alloy was prepared in a planetary Fritsch P6 mill at a disk rotation of $520 \mathrm{rpm}$ from mixtures of appropriate amounts of $\mathrm{Fe}(>99.0 \%$, power, grain size $60 \mu \mathrm{m})$ and $\mathrm{Cr}(>99.0 \%$, powder, $<45 \mu \mathrm{m})$. The average powder mass was $25 \mathrm{~g}$ and the powder-to-ball weight ratio was $1 / 20$. The powder was sealed in the vial under a pure argon atmosphere. The total milling time was $16 \mathrm{~h}$ interrupted $10 \mathrm{~min}$ every $30 \mathrm{~min}$. The content of oxygen determined for this sample was 1.0 at $\%$. The nanocrystalline bcc alloy was then annealed in vacuum at $700{ }^{\circ} \mathrm{C}$ for $6 \mathrm{~h}$, an annealing time much shorter than those needed for coarsegrained alloys to form the sigma phase [10]. The full transformation of the bcc 
phase into the sigma phase was checked by X-ray diffraction and Mössbauer spectroscopy. This nanocrystalline sigma phase sample was then submitted to the same milling procedures as those described above (series $S_{\mathrm{nc}}$ ).

Microprobe analyses were used to determine the compositions of the alloys. The oxygen contents after milling and in the starting $S_{\mathrm{nc}}$ powders were obtained by combustion of the samples in an oxygen determinator equipped with a solid state infrared detector

$\mathrm{X}$-ray diffraction (XRD) was performed at room temperature (RT) using $\mathrm{Cu} \mathrm{K} \alpha$ radiation $(\lambda=0.154184 \mathrm{~nm})$ to characterize the microstructural changes induced by the ball milling and to determine the mean crystallite size and microstrain of the final samples. These were obtained from the widths of the XRD peaks using the Williamson-Hall method [43].

Mössbauer spectroscopy was further used to identify the various phases. ${ }^{57} \mathrm{Fe}$ spectra were recorded at $\mathrm{RT}$ and at $35 \mathrm{~K}$ in a transmission geometry using a standard constant acceleration spectrometer. $\mathrm{A}^{57} \mathrm{Co}$ source in Rh matrix with a strength of $\approx 35 \mathrm{mCi}$ was used. The experimental spectra were analyzed by a constrained Hesse-Rübartsch method [44], which yields a hyperfine magnetic field distribution (HMFD), $\mathrm{P}(\mathrm{B})$. Lorentzian line-shapes were employed in this procedure. As usual, the ${ }^{57} \mathrm{Fe}$ isomer shifts are given with respect to $\alpha$-Fe at RT.

Differential scanning calorimetry (DSC) was used to study the transformations of the final as-milled samples during heating in an argon flow from room temperature to $800^{\circ} \mathrm{C}$ with a heating rate of $40^{\circ} \mathrm{C} / \mathrm{min}$.

The saturation magnetizations of the as-milled samples were determined with a SQUID magnetometer at a temperature of $4.2 \mathrm{~K}$.

\section{Results and discussion}

The final compositions of the ball-milled alloys $S_{\mathrm{cg} 1}(250 \mathrm{~h})$, $S_{\mathrm{cg} 2}(100 \mathrm{~h})$ and $S_{\mathrm{nc}}(40 \mathrm{~h})$ were determined by microprobe analysis to be $\mathrm{Fe}_{0.56} \mathrm{Cr}_{0.44}, \mathrm{Fe}_{0.55} \mathrm{Cr}_{0.45}$ and $\mathrm{Fe}_{0.53} \mathrm{Cr}_{0.47}$, respectively. The oxygen contents of these samples are 1.0 at $\%, 1.2$ at $\%$ and 1.8 at $\%$, respectively, while their nitrogen contents are $0.04 \mathrm{wt} \%$, $0.06 \mathrm{wt} \%$ and $0.105 \mathrm{wt} \%$. They are fairly comparable with the concentrations of oxygen, $1.11 \mathrm{wt} \%$, and of nitrogen, $0.06 \mathrm{wt} \%$, measured in iron ground for $100 \mathrm{~h}$ in high-purity argon in an attrition mill [20]. The low nitrogen contents indicate that the vial is air tight.

\subsection{X-ray diffraction}

Figs. 1-3 show the X-ray diffraction patterns for different periods of ball milling $t_{\mathrm{m}}$ for the samples of the three series. Figs. 1 and 2 stand for the series $S_{\mathrm{cg} 1}(A=2.5)$ and $S_{\mathrm{cg} 2}(A=3)$, respectively. Fig. 3 corresponds to the $S_{\text {nc }}$ series $(A=3)$. For comparison the XRD pattern of the bcc as-cast alloy is also shown in each figure. The intensities of the $\sigma$-phase diffraction peaks decrease with increasing $t_{\mathrm{m}}$ and the peaks of the bcc $\alpha$ phase appear. Fig. 1 shows that only the bcc peaks are visible for $S_{\mathrm{cg} 1}(55 \mathrm{~h})$. After longer milling times (Fig. 1b), the samples remain bcc but the peaks are broadened due to the reduction of crystallite size and to the effect of strain. As expected, the XRD peaks of the coarse-grained as-cast alloy are narrower than those of ball-milled samples. The mean grain size determined from the linewidths of the peaks of $S_{\mathrm{cg} 1}(250 \mathrm{~h})$ is $7 \mathrm{~nm}$ and the microstrain is $1.3 \%$. Fig. 2 shows that the transformation is much faster for the $S_{\mathrm{cg} 2}$ series than for the $S_{\mathrm{cg} 1}$ one as the injected power increases with $A$. After $25 \mathrm{~h}$ of milling only the bcc phase is seen on the XRD patterns of $S_{\mathrm{cg} 2}$ samples. As before, for longer $t_{\mathrm{m}}$ (Fig. 2b) the bcc peaks broaden. The mean grain size of the sample $S_{\mathrm{cg} 2}(100 \mathrm{~h})$ is also $7 \mathrm{~nm}$ and the
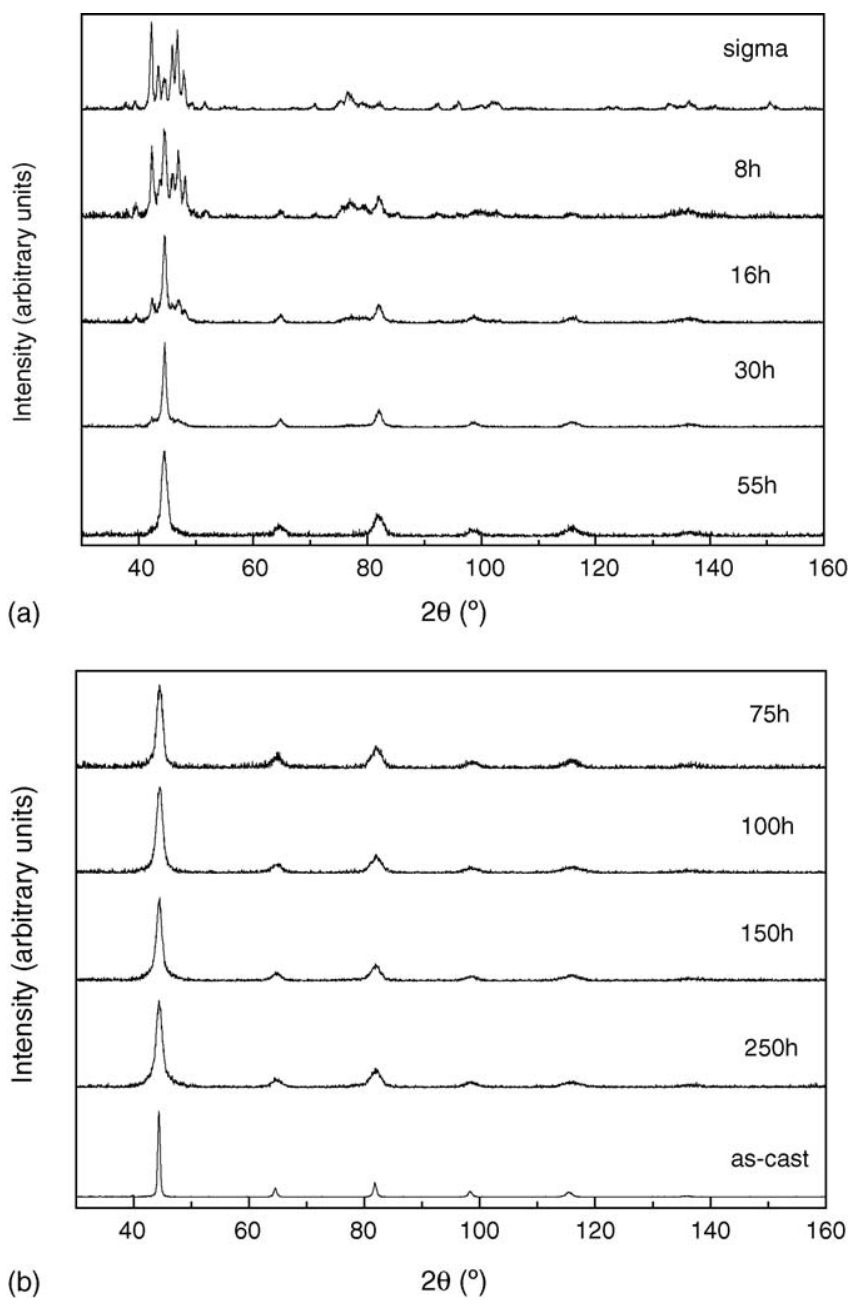

Fig. 1. X-ray diffraction patterns of a coarse-grained sigma $\mathrm{FeCr}$ sample after different milling times at an amplitude of vibration of the mill $A=2.5\left(S_{\mathrm{cg} 1}\right.$ series). The top pattern (a) is that of the starting tetragonal sigma phase. The bottom pattern (b) is that of an as-cast bec $\mathrm{FeCr}$ alloy.

microstrain is $1.3 \%$. Fig. 3 shows that the nanocrystalline sample transforms even faster than the two coarse-grained alloys despite identical milling amplitudes for the $S_{\mathrm{cg} 2}$ and $S_{\mathrm{nc}}$ series. The starting nanocrystalline sigma phase has a mean grain size and a microstrain of $34 \mathrm{~nm}$ and $0.91 \%$, respectively. After $15 \mathrm{~h}$ of milling only the bcc phase is observed and the peaks broaden as well for longer $t_{\mathrm{m}}$. The mean grain size of the sample $S_{\mathrm{nc}}(40 \mathrm{~h})$ is $7 \mathrm{~nm}$ and the mean microstrain is $1.3 \%$ as they are for $S_{\mathrm{cg} 1}(250 \mathrm{~h})$ and $S_{\mathrm{cg} 2}(100 \mathrm{~h})$.

\subsection{Mössbauer spectroscopy}

Figs. 4-6 show RT ${ }^{57}$ Fe Mössbauer spectra and hyperfine magnetic field distributions of the different series of samples milled for the indicated periods. The first spectrum in each figure corresponds to the starting sigma phase which is paramagnetic at RT with an average isomer shift of $-0.17(2) \mathrm{mm} / \mathrm{s}$. A broad magnetic component, which corresponds to the magnetic alpha phase, appears with increasing $t_{\mathrm{m}}$. The contribution of this phase increases until about $55 \mathrm{~h}, 25 \mathrm{~h}$ and $15 \mathrm{~h}$ of milling for the first, 

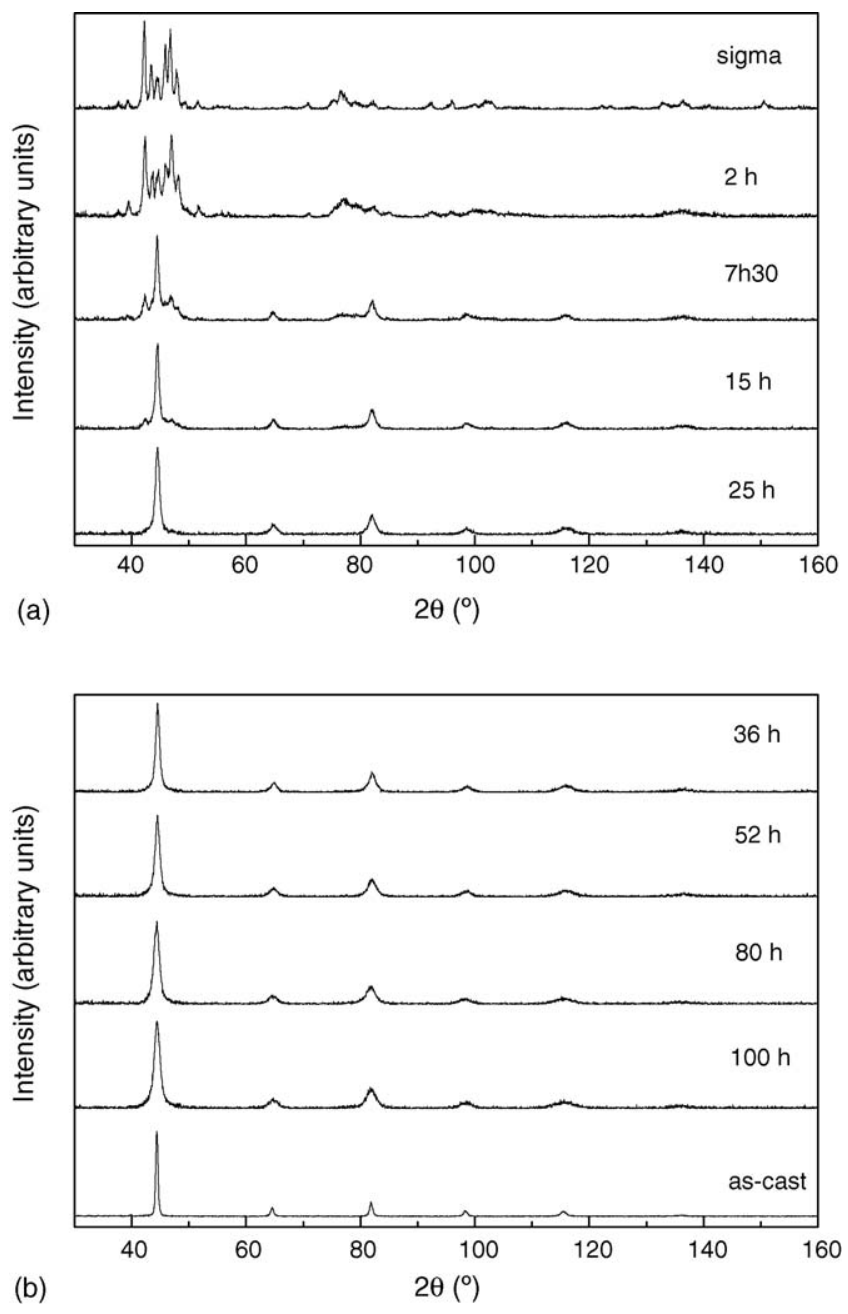

Fig. 2. X-ray diffraction patterns of a coarse-grained sigma FeCr sample after different milling times at the maximum amplitude of vibration of the mill $(A=3)$ $\left(S_{\mathrm{cg} 2}\right.$ series). The top pattern (a) is that of the starting tetragonal sigma phase. The bottom pattern (b) is that of an as-cast bcc FeCr alloy.

second and third series, respectively. At this stage, the shape of the central peak changes. The paramagnetic contribution can no more be attributed to the sole sigma phase but another phase forms whose contribution increases with $t_{\mathrm{m}}$. XRD patterns do not show the peaks of the sigma phase but only broadened peaks of a bcc phase. The area fractions of the magnetic and of the paramagnetic parts of the spectrum of a sample milled for a time $t$ are denoted hereafter $A_{\mathrm{F}}(t)$ and $A_{\mathrm{P}}(t)\left(\right.$ Fig. 7) $\left(A_{\mathrm{F}}(t)+A_{\mathrm{P}}(t)=1\right)$, respectively.

The evolution with milling time of the average hyperfine magnetic field $\langle B\rangle$ of the magnetic part of the spectra recorded from samples of the three series is shown in Fig. 8 and may be summarized as follows:

- For the $S_{\mathrm{cg} 1}$ series, $\langle B\rangle$ increases and reaches a plateau at $\langle B\rangle=17.4(3) \mathrm{T}$ for $55 \mathrm{~h} \leq t_{\mathrm{m}} \leq 150 \mathrm{~h}$ and then increases $\left(A_{\mathrm{P}}(150 \mathrm{~h})=0.34\right)$. The Mössbauer parameters of the sample $S_{\text {cg1 }}(250 \mathrm{~h}$ ) (Fig. 4) are $\langle B\rangle=20.1 \mathrm{~T}$ and $\langle\mathrm{IS}\rangle=-0.064 \mathrm{~mm} / \mathrm{s}$ for the magnetic subspectrum while $\langle\mathrm{IS}\rangle=-0.114 \mathrm{~mm} / \mathrm{s}$ for the paramagnetic subspectrum $\left(A_{\mathrm{P}}(250 \mathrm{~h})=0.35\right)$.
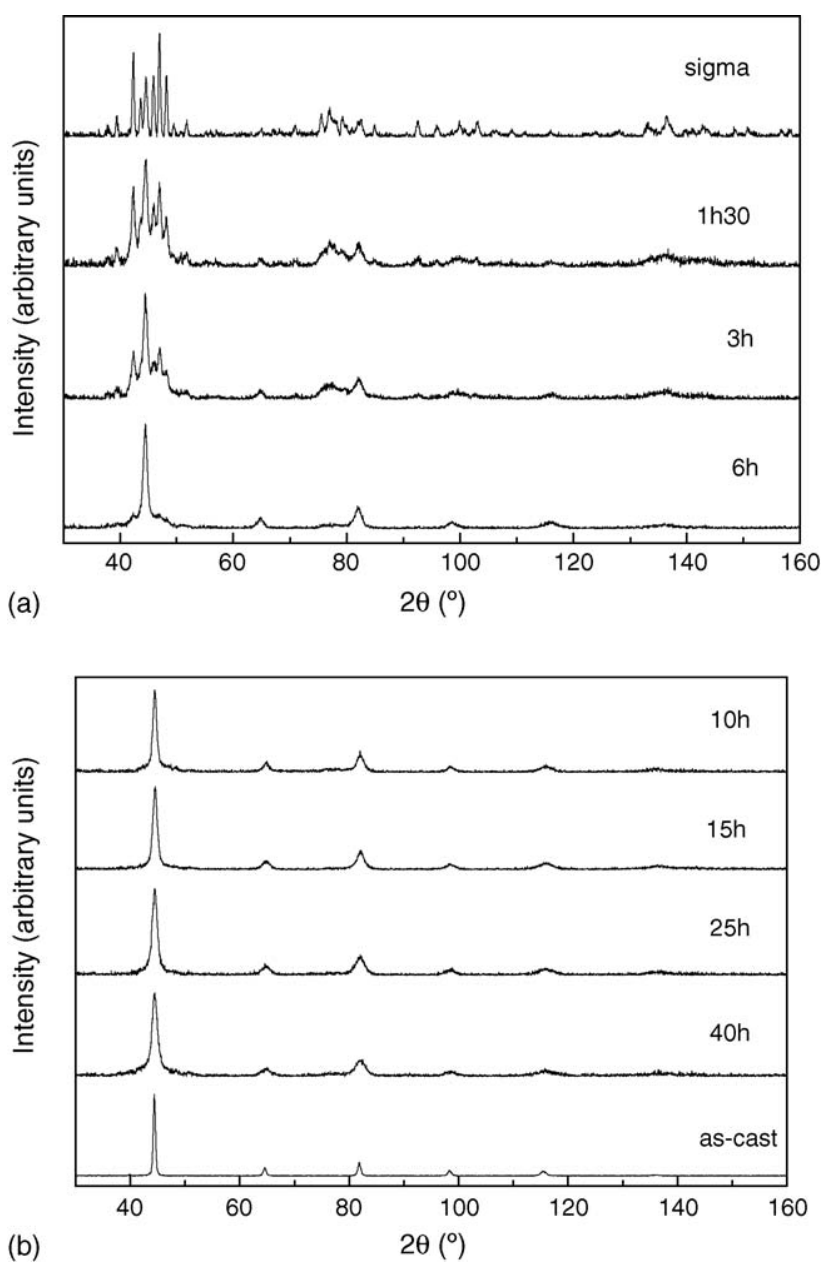

Fig. 3. X-ray diffraction patterns of the nanocrystalline sigma $\mathrm{FeCr}$ sample after different milling times at the maximum vibration amplitude of the mill $(A=3)$ ( $S_{\mathrm{nc}}$ series). The top pattern (a) is that of the starting tetragonal sigma phase. The bottom pattern (b) is that of an as-cast bcc FeCr alloy.

- For the $S_{\mathrm{cg} 2}$ series, $\langle B\rangle=18.3(3) \mathrm{T}$ is essentially constant for $t_{\mathrm{m}} \geq 10 \mathrm{~h} \quad\left(A_{\mathrm{P}}(100 \mathrm{~h})=0.34\right)$. For $S_{\mathrm{cg} 2}(100 \mathrm{~h})$ (Fig. 5), the parameters are, respectively, $\langle B\rangle=18.5 \mathrm{~T}$ and $\langle\mathrm{IS}\rangle=-0.020 \mathrm{~mm} / \mathrm{s}$ for the magnetic subspectrum and $\langle\mathrm{IS}\rangle=-0.077 \mathrm{~mm} / \mathrm{s}$ for the paramagnetic one.

- For the $S_{\text {nc }}$ series, $\langle B\rangle$ is essentially constant, namely $\langle B\rangle=18.3(5) \mathrm{T}$, for $1 \mathrm{~h} 30 \leq t_{\mathrm{m}} \leq 25 \mathrm{~h}\left(A_{\mathrm{P}}(25 \mathrm{~h})=0.25\right)$ and then increases to reach the following values at $t_{\mathrm{m}}=40 \mathrm{~h}$ : $\langle B\rangle=20.4 \mathrm{~T}$ and $\langle\mathrm{IS}\rangle=-0.057 \mathrm{~mm} / \mathrm{s}$ and $\langle\mathrm{IS}\rangle=-0.081 \mathrm{~mm} / \mathrm{s}$ $\left(A_{\mathrm{P}}(40 \mathrm{~h})=0.36\right)($ Fig. 6).

\subsubsection{The magnetic component of Mössbauer spectra}

The plateau values are associated with typical $\mathrm{Cr}$ contents of $x=0.48$ (2) as deduced from the published results on the concentration dependence of ${ }^{57} \mathrm{Fe}$ hyperfine fields of $\mathrm{Fe}-\mathrm{Cr}$ bcc alloys at RT [45-49]. They are in good agreement with the values expected from the starting compositions. The increases of the average fields for long milling times might, as expected, be attributed to a contamination of the milled alloys by the steel of milling tools which increases the $\mathrm{Fe}$ content. Clear contributions $\mathrm{P}_{\mathrm{Fe}}$ due to $\mathrm{Fe}$-rich bcc phases are indeed seen at 


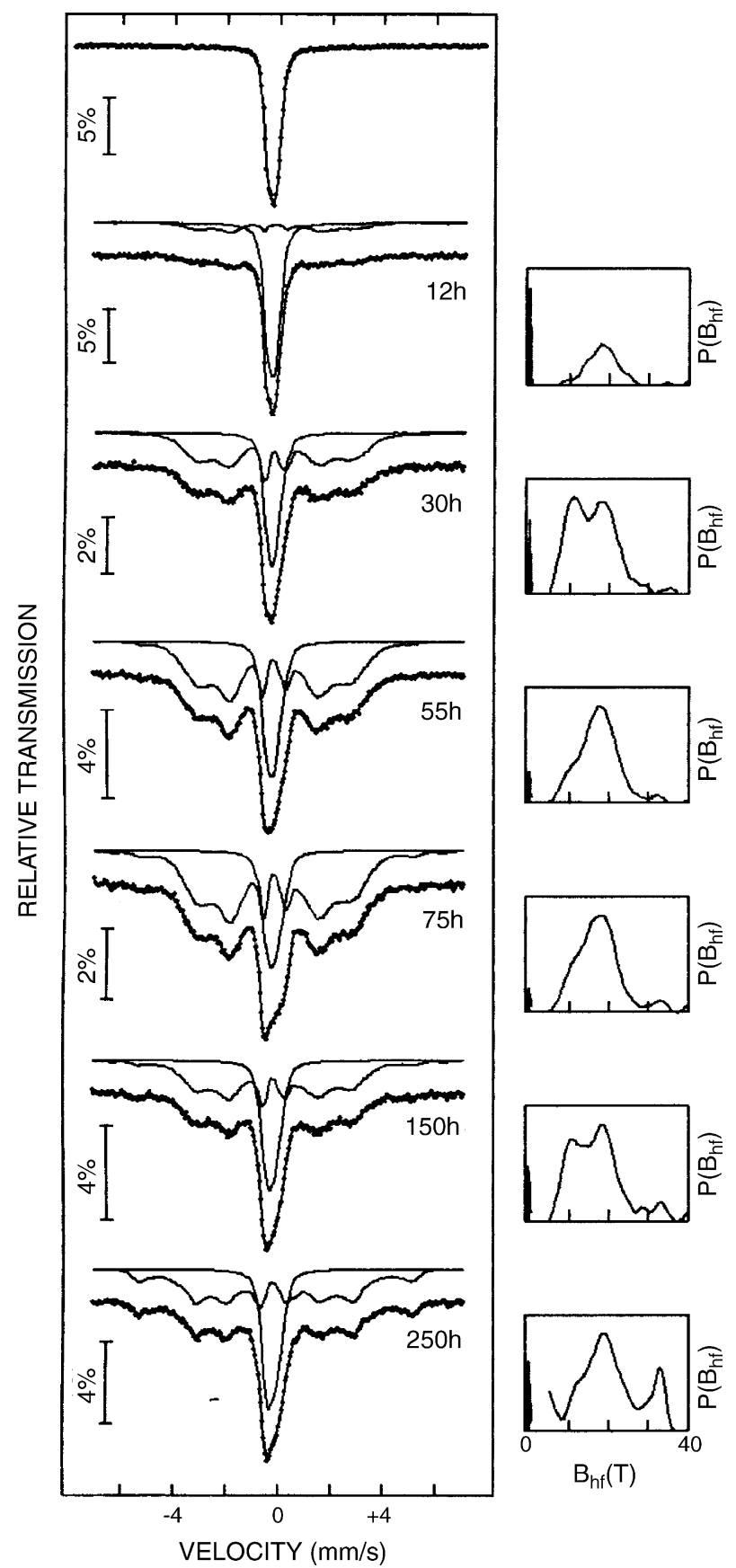

Fig. 4. ${ }^{57} \mathrm{Fe}$ RT Mössbauer spectra of $S_{\mathrm{cg} 1}$ samples and hyperfine magnetic field distributions as a function of milling time. The top spectrum corresponds to the starting sigma phase.

high hyperfine fields for long milling times on the HMFD's of $S_{\mathrm{cg} 1}(250 \mathrm{~h})$ and $S_{\mathrm{nc}}(40 \mathrm{~h})$ (Figs. 4 and 6). It is rather difficult to know precisely if the Fe contents of the bcc alloy and of the paramagnetic phase increase in the same way. In any case, the observed increases of the average hyperfine fields of samples $S_{\mathrm{cg} 1}(250 \mathrm{~h})$ and $S_{\mathrm{nc}}(40 \mathrm{~h})$ and the observed weights of peaks $\mathrm{P}_{\mathrm{Fe}}$ (Figs. 4 and 6) are too large to be solely attributed to a contamination effect with an increase of the Fe content which is only of the order of $1 \%$. A depletion of the $\mathrm{Cr}$ content inside grains might be related to the formation of $\mathrm{Cr}_{2} \mathrm{O}_{3}$ at grain boundaries for long milling times. A preferential oxidation of $\mathrm{Cr}$ occurred

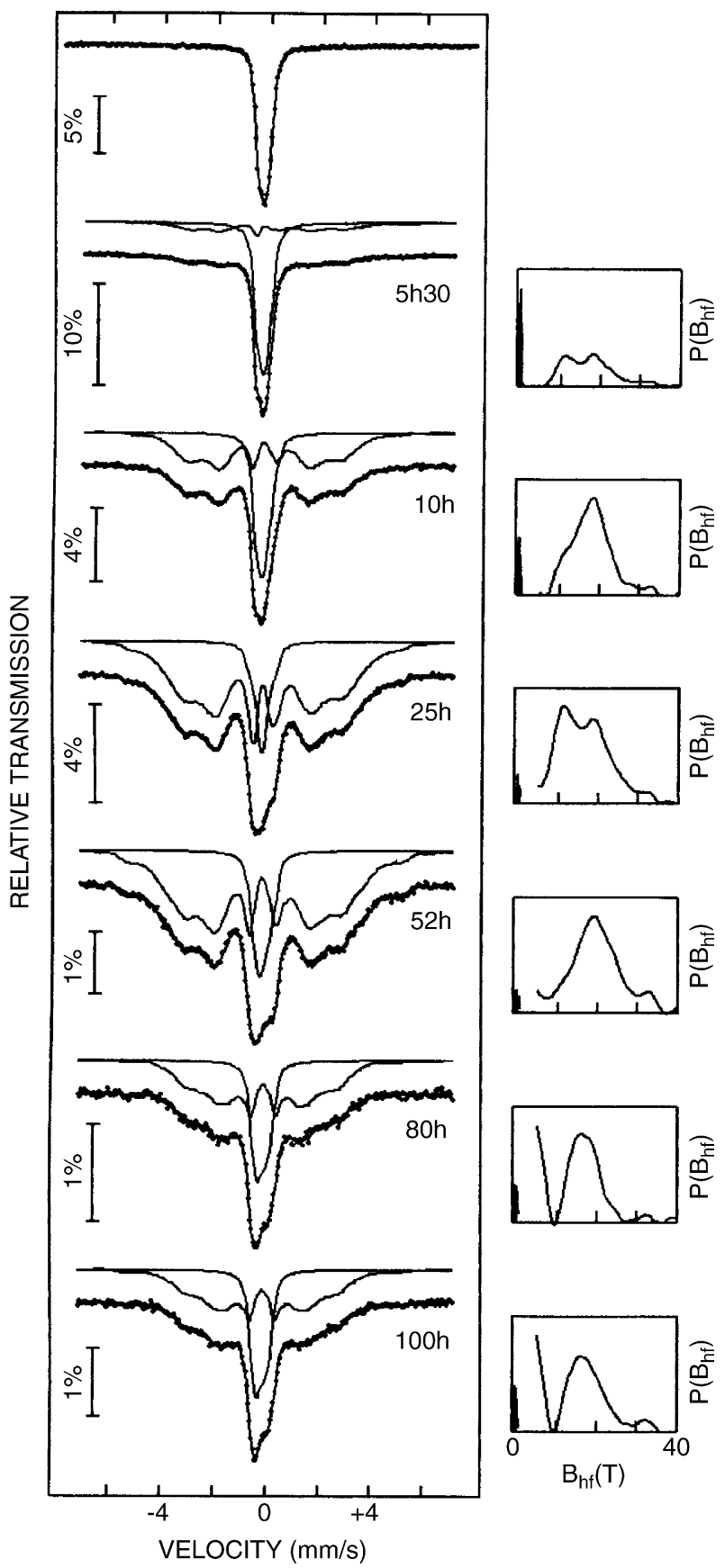

Fig. 5. ${ }^{57} \mathrm{Fe}$ RT Mössbauer spectra of $S_{\mathrm{cg} 2}$ samples and hyperfine magnetic field distributions as a function of milling time. The top spectrum corresponds to the starting sigma phase.

indeed in ball-milled $\mathrm{Fe}_{0.95} \mathrm{Cr}_{0.05}$ but during annealing in argon [39].

Another explanation would be that the bcc components of the alloys milled for sufficiently long times start to separate into bcc phases with compositions, respectively, richer in $\mathrm{Fe}$ and richer in $\mathrm{Cr}$ than the average composition. The change, at an annealing time $t$, of the average RT hyperfine field of a coarse-grained $\mathrm{Fe}_{0.55} \mathrm{Cr}_{0.45}$ alloy undergoing phase separation at $475^{\circ} \mathrm{C}$ was shown in [11] to be given by $\Delta B(t)=\langle B(t)\rangle-\langle B(0)\rangle=38.6 \sigma^{2}(t)$, where $\sigma^{2}(t)$ is the variance of the distribution of the $\mathrm{Cr}$ content in the alloy at time $t$ with $\sigma^{2}(0)=0$ and $\sigma^{2}(\infty)=0.137$, that is 


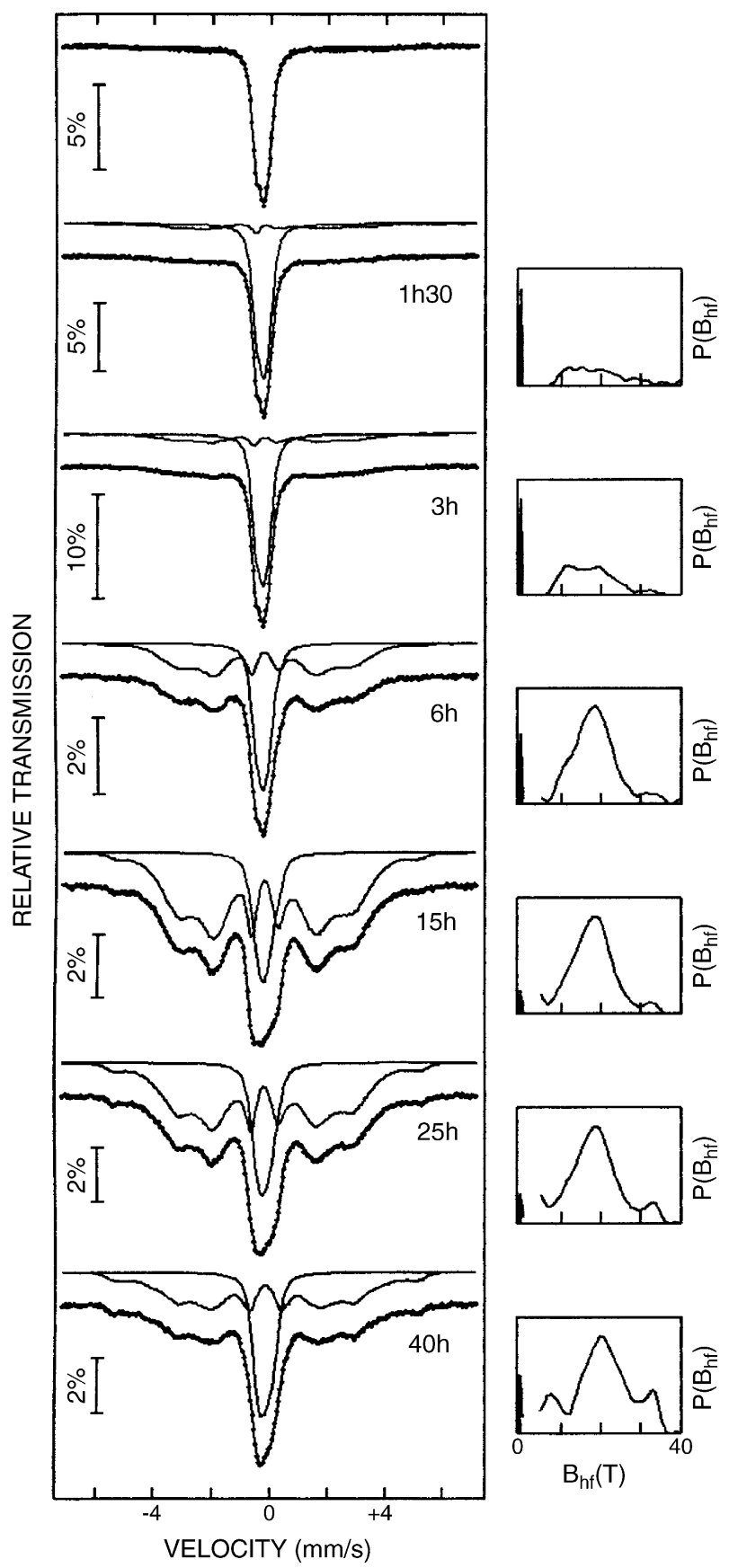

Fig. 6. ${ }^{57} \mathrm{Fe}$ RT Mössbauer spectra of $S_{\mathrm{nc}}$ samples and hyperfine magnetic field distributions as a function of milling time. The top spectrum corresponds to the starting sigma phase.

$\Delta B(\infty)=5.3 \mathrm{~T}$. Similar maximum values of the changes in average hyperfine fields are expected for a variety of conditions in phase-separated near-equiatomic alloys. Values of $\sim 2.1 \mathrm{~T}$ and $2.7 \mathrm{~T}$ found here would be consistent with that assumption. Further, the Cr-rich component of partially unmixed bcc phases in $S_{\mathrm{cg} 1}(250 \mathrm{~h})$ and $S_{\mathrm{nc}}(40 \mathrm{~h})$ might slightly contribute to the central components of the corresponding spectra. Due to the selectivity of Mössbauer spectroscopy, the weights of such Cr-rich phases are however less than that of Fe-rich phases but they could contribute to the increase of $A_{\mathrm{P}}(t)$ for long milling times (Fig. 7). We cannot therefore exclude that phase-separated alloys are possi-
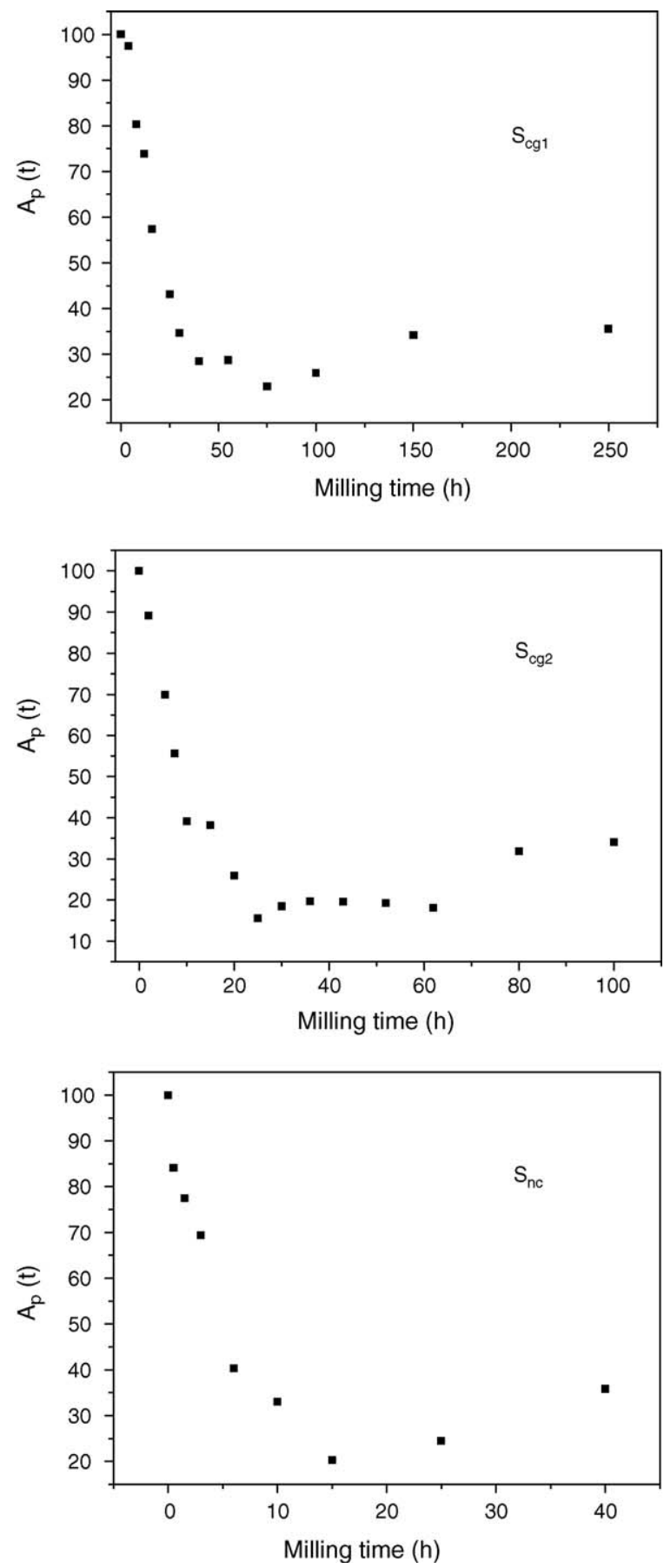

Fig. 7. Paramagnetic area fraction $A_{\mathrm{P}}(t)$ as a function of milling time for the indicated samples.

ble dynamical equilibrium states of ball-milled $\mathrm{Fe}-\mathrm{Cr}$ alloys for near-equiatomic alloys and not only for $\mathrm{Cr}$-rich alloys as shown for $\mathrm{Fe}_{0.30} \mathrm{Cr}_{0.70}$ [19].

\subsubsection{The non-magnetic component of Mössbauer spectra}

The area fractions of the central peaks are significant for the alloys milled for long times (Fig. 7). As no X-ray diffraction peaks different from those of bcc phases are observed, the central Mössbauer peaks might be attributed to bcc phases whose $\mathrm{Cr}$ contents are larger than $\sim 0.65$ and are thus paramagnetic 

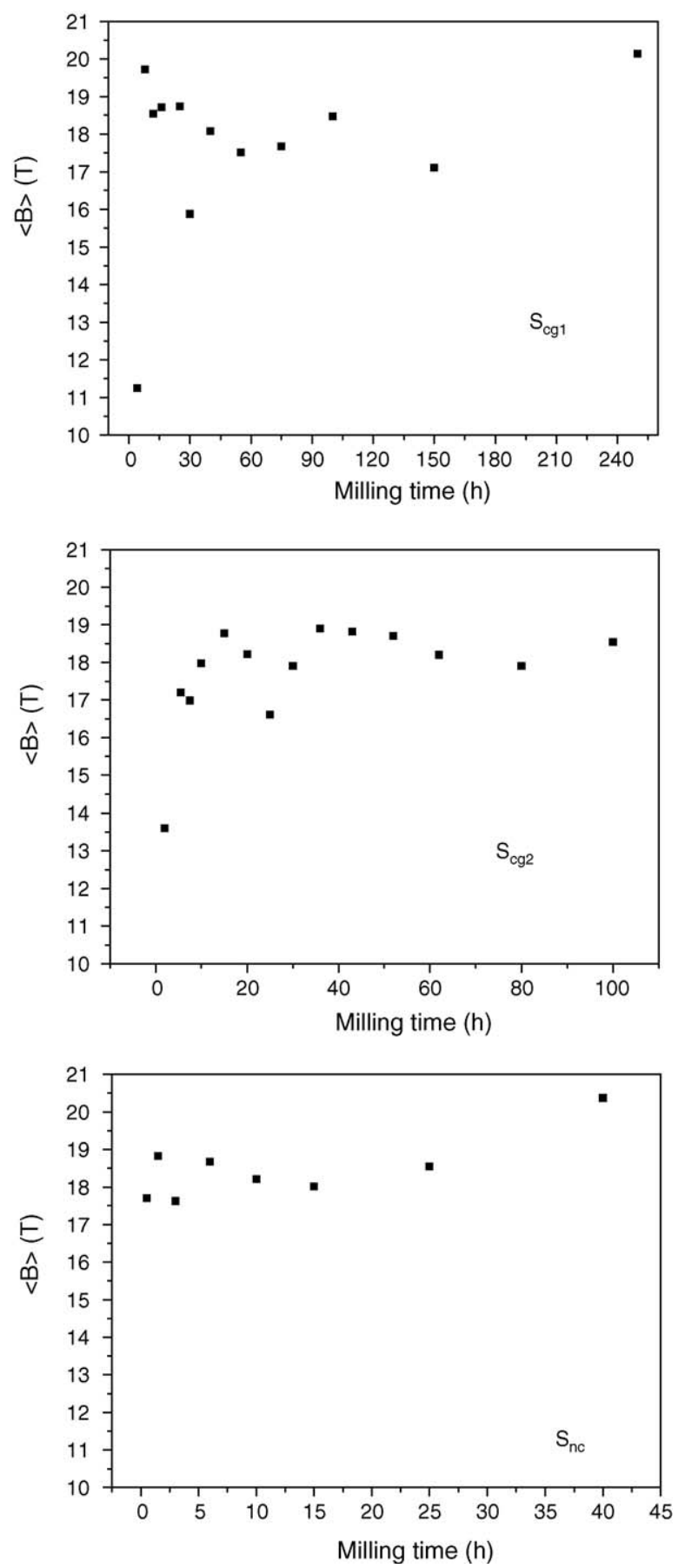

Fig. 8. Mean hyperfine magnetic fields as a function of the milling time for the indicated samples.

(eventually superparamagnetic [19]) at RT, to a phase with small crystallites and diffraction intensities distributed between many lines so that its X-ray pattern would be blurred and difficult to evidence, to an amorphous phase [30,31] or to a contribution from $\mathrm{Fe}$ atoms at grain boundaries and in their vicinities whose magnetic and hyperfine magnetic properties are influenced by oxygen [24-26]. The mean isomer shifts are rather close to the average isomer shift, $\langle\mathrm{IS}\rangle=-0.12(2) \mathrm{mm} / \mathrm{s}$, of a $\mathrm{Fe}_{0.51} \mathrm{Cr}_{0.49}$ thin film with an A15 structure deposited by ionbeam sputtering [50]. The RT spectrum of this A15 phase shows however a shoulder at negative velocities which does not account for the spectral shapes we observe. The mean isomer shifts, which agree with those obtained by Xia et al. [30] for an amorphous phase formed by thermal evaporation and condensation on a cold substrate, would favour the latter phase. A Mössbauer spectrum of $S_{\mathrm{cg} 1}(150 \mathrm{~h})$ recorded at $35 \mathrm{~K}$ yields $\langle B\rangle=20.5 \mathrm{~T}$, $\langle\mathrm{IS}\rangle_{\mathrm{F}}=0.042 \mathrm{~mm} / \mathrm{s},\langle\mathrm{IS}\rangle_{\mathrm{P}}=-0.025 \mathrm{~mm} / \mathrm{s}$ and $A_{\mathrm{P}}(150 \mathrm{~h})=0.30$ as compared to 0.34 at RT. The non-magnetic component at $35 \mathrm{~K}$ is consistent with the low-temperature Mössbauer spectrum of an amorphous $\mathrm{Fe}_{0.50} \mathrm{Cr}_{0.50}$ thin film which exhibits only a central absorption line down to $4.2 \mathrm{~K}$ [30]. The slight decrease of $\mathrm{A}_{\mathrm{P}}(150 \mathrm{~h})$ suggests the existence of a superparamagnetic contribution which might still increase at lower temperature.

The 'disordered' part of the bcc $\mathrm{Fe}_{0.60} \mathrm{Cr}_{0.40}$ alloy milled in argon by Shen et al. [26], which gives rise to a very intense central Mössbauer peak at RT, would surprisingly represent the overwhelming fraction of the mechanically alloyed sample as deduced from the central Mössbauer peak in contradiction with the XRD pattern which shows only the diffraction peaks of a bcc phase [26]. A way to reconcile both results is to assume that a 'disordered' (or an amorphous) phase forms indeed at GB's so that a larger and larger fraction of the grain interiors become magnetically uncoupled from each other when the thickness and fraction of the disordered phase increase. A resulting superparamagnetic relaxation would explain the observed RT Mössbauer spectrum. A nanoscale phase separation might enhance the latter uncoupling as seen for instance in $\mathrm{Fe}_{0.30} \mathrm{Cr}_{0.70}$ ([19] and references therein). A significant superparamagnetic contribution to the RT Mössbauer spectrum will then have to be looked for in these $\mathrm{Fe}_{0.60} \mathrm{Cr}_{0.40}$ alloys ground in argon [26].

In our study, only oxygen is left as an infused residual gas which possibly influences partly the structure of these $\mathrm{Fe}-\mathrm{Cr}$ nanocrystalline alloys. Its concentration is expected to increase slightly but steadily with the milling time as a consequence of our experimental protocol. For a grain boundary of thickness $e$ and for a grain diameter $d$, the volume fraction of the grain boundary region would be of the order of $3 e / 2 d$. As the paramagnetic fraction is $\sim 0.30$, the width $e$ is estimated to be $\sim 1.4 \mathrm{~nm}$ for $d=7 \mathrm{~nm}$, that is $e \sim 6 b$, where $b$ is the length of a Burgers vector, a value larger than but not so different from the estimated width used by Fan et al. in their model of the inverse Hall-Petch behaviour, $e \sim 3 b$ [51]. In our conditions, the local oxygen concentration at grain boundaries might reach $\sim 6$ at $\%$. It is difficult to understand how such a moderate oxygen concentration would change the overall grain boundary structure to a point that their magnetic properties change significantly. A reasonable assumption is again that oxygen favours the formation of an amorphous phase at grain boundaries as the latter act as preferred diffusion paths for gases. Grains would thus be progressively surrounded by amorphous layers.

\subsection{Annealing}

Annealing experiments were performed to further check the assumption of the presence of an amorphous phase. DSC traces obtained for the samples $S_{\mathrm{cg} 1}(250 \mathrm{~h}), S_{\mathrm{cg} 2}(100 \mathrm{~h})$ and $S_{\mathrm{nc}}(40 \mathrm{~h})$ are shown in Fig. 9. Two exothermal peaks are observed at 


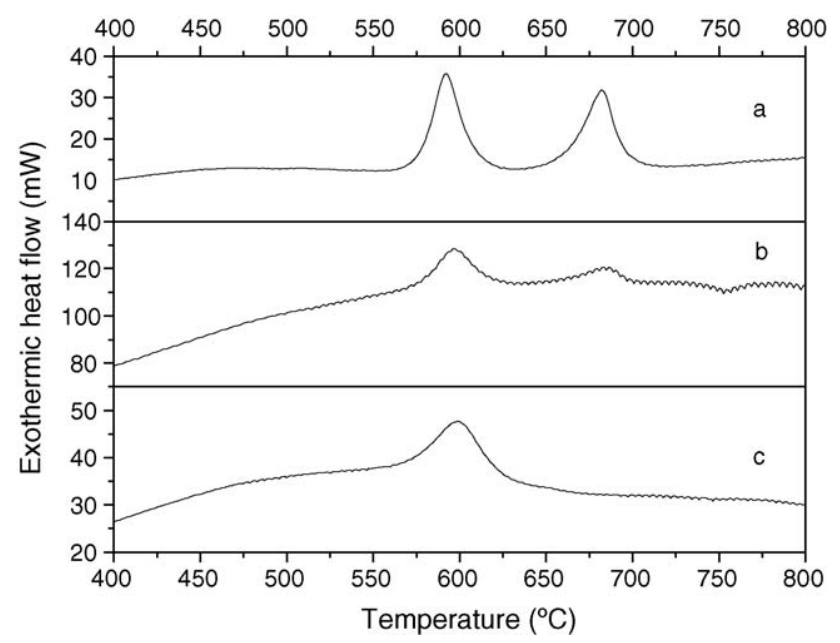

Fig. 9. DSC traces of: (a) $S_{\mathrm{cg} 1}(250 \mathrm{~h})$, (b) $S_{\mathrm{cg} 2}(100 \mathrm{~h})$, (c) $S_{\mathrm{nc}}(40 \mathrm{~h})$.

$600^{\circ} \mathrm{C}$ and $680^{\circ} \mathrm{C}$ for $S_{\operatorname{cg} 1}(250 \mathrm{~h})$ and $S_{\operatorname{cg} 2}(100 \mathrm{~h})$ while only the first is seen for $S_{\mathrm{nc}}(40 \mathrm{~h})$.

The samples $S_{\mathrm{cg} 1}(250 \mathrm{~h}), S_{\mathrm{cg} 2}(100 \mathrm{~h})$ and $S_{\mathrm{nc}}(40 \mathrm{~h})$ were annealed at $600^{\circ} \mathrm{C}$ in vacuum for $6 \mathrm{~min}$. X-ray diffraction patterns were recorded subsequently at RT and only show bec XRD patterns. Mean crystallite sizes were calculated to be $33 \mathrm{~nm}$, $13 \mathrm{~nm}$ and $17 \mathrm{~nm}$ and microstrains were $0.59 \%, 0.66 \%$ and $0.91 \%$ for $S_{\mathrm{cg} 1}(250 \mathrm{~h}), S_{\mathrm{cg} 2}(100 \mathrm{~h})$ and $S_{\mathrm{nc}}(40 \mathrm{~h})$, respectively. The area fraction of the paramagnetic component of the RT Mössbauer spectrum of annealed $S_{\mathrm{cg} 2}(100 \mathrm{~h})$ decreases from 0.34 before annealing to 0.11 after.

The samples $S_{\mathrm{cg} 1}(250 \mathrm{~h})$ and $S_{\mathrm{cg} 2}(100 \mathrm{~h})$ were also annealed at $680^{\circ} \mathrm{C}$ in vacuum for $12 \mathrm{~min}$. X-ray diffraction patterns were recorded subsequently at RT (Fig. 10). Fig. 10 only shows bcc XRD patterns. Mean crystallite sizes were calculated to be $28 \mathrm{~nm}$ and $10 \mathrm{~nm}$ and microstrains were $0.31 \%$ and $0.44 \%$ for $S_{\mathrm{cg} 1}(250 \mathrm{~h})$ and $S_{\mathrm{cg} 2}(100 \mathrm{~h})$, respectively.

The most striking result of the annealing experiment is the absence of the sigma phase which is further discussed in Section 3.5. The existence of two crystallization steps of the 'amorphous'

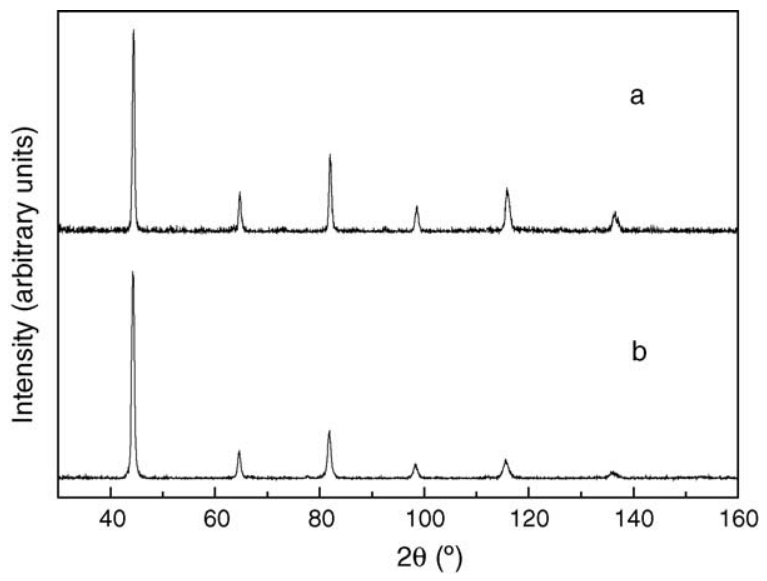

Fig. 10. X-ray diffraction patterns of the following samples annealed at $680^{\circ} \mathrm{C}$ for $12 \mathrm{~min}$ : (a) $S_{\mathrm{cg} 1}(250 \mathrm{~h})$ and (b) $S_{\mathrm{cg} 2}(100 \mathrm{~h})$. component might again be attributed to a phase separation occurring before crystallization.

\subsection{Saturation magnetization}

Bakker et al. [13,32,33] followed the transformation, by ball-milling in vacuum, of a coarse-grained $\mathrm{FeCr}$ sigma phase by X-ray diffraction and by magnetization measurements. Our XRD results are similar to theirs from which they concluded to the transformation of the sigma phase into a sole bcc solid solution. They also attributed the small values of the saturation of magnetization to the fact that the domains are nanometersized with a resulting very high density of grain boundaries (Section 1).

We determined saturation magnetizations at $4.2 \mathrm{~K}$ of $1.45 \mu_{\mathrm{B}} / \mathrm{at} \mathrm{Fe}$ and of $1.13 \mu_{\mathrm{B}} / \mathrm{at} \mathrm{Fe}$ for the $S_{\mathrm{cg} 1}(250 \mathrm{~h})$ and $S_{\mathrm{cg} 2}(100 \mathrm{~h})$ samples, respectively. These values are close to that, $1.20 \mu_{\mathrm{B}} / \mathrm{at} \mathrm{Fe}$, obtained by Yang and Bakker [32]. For the samples $S_{\mathrm{cg} 1}(250 \mathrm{~h})$ and $S_{\mathrm{cg} 2}(100 \mathrm{~h})$ annealed at $600^{\circ} \mathrm{C}$ for $6 \mathrm{~min}$, we measured, respectively, $2.05 \mu_{\mathrm{B}} / \mathrm{at} \mathrm{Fe}$ and $1.87 \mu_{\mathrm{B}} /$ at Fe. The $0 \mathrm{~K}$ magnetization given by Aldred [34] for bulk bcc alloys of the same composition is close to $2 \mu_{\mathrm{B}} / \mathrm{at} \mathrm{Fe}$. The amorphous phase is thus not fully crystallized in annealed $S_{\mathrm{cg} 2}(100 \mathrm{~h})$ as the area fraction of the paramagnetic Mössbauer component is still 32\% of that of the as-milled sample.

\subsection{Final discussion}

The rationale for phase formation in ball-milled nearequiatomic $\mathrm{Fe}-\mathrm{Cr}$ alloys, either bcc or sigma, must take into account apparently conflicting results. The final phases are reported to be either a bcc phase or a bcc phase with a 'disordered' component whose fraction may vary considerably according to the authors. For instance, Koyano et al. [28] showed that a sole ferromagnetic bcc phase is formed by ballmilling of equiatomic $\mathrm{Fe}-\mathrm{Cr}$ elemental powder mixtures during $200 \mathrm{~h}$ in argon in a Fritsch P5 planetary ball-mill. By contrast, Shen et al. [26] found an almost fully non-magnetic RT Mössbauer spectrum and a bcc X-ray diffraction pattern by ballmilling of $\mathrm{Fe}_{0.60} \mathrm{Cr}_{0.40}$ elemental powder mixtures during $85 \mathrm{~h}$ in argon.

The average field $\langle B\rangle=20.9 \mathrm{~T}$ found by Shen et al. [26] for $\mathrm{Fe}_{0.60} \mathrm{Cr}_{0.40}$ mechanically alloyed in vacuum is the field expected, $20.9 \mathrm{~T}$, from the literature values for coarse-grained alloys [45-49]. Further, as X-ray diffraction patterns show only bcc peaks, it must be concluded that the hyperfine properties of grain boundary regions do not differ significantly from those of grain interiors in such concentrated nanocrystalline alloys. The nitrogen (some $0.01 \mathrm{wt} \%$ ) and argon concentrations are too low in alloys ball-milled in argon in air-tight vials to influence significantly the hyperfine properties as shown clearly by Rawers et al. for iron ball-milled in argon [21,22]. The Mössbauer spectrum of an elemental powder mixture $\mathrm{Fe}_{0.60} \mathrm{Cr}_{0.40}$, milled for $85 \mathrm{~h}$ in argon [26], shows, besides the main non-magnetic peak, a weaker and broad magnetic contribution with an average field of $\sim 12.5 \mathrm{~T}$, much smaller than the field expected for that $\mathrm{Cr}$ content. A rather similar Mössbauer spectrum was obtained 
by Koyano et al. [28] with a nanocrystalline $\mathrm{Fe}_{0.50} \mathrm{Cr}_{0.50}$ alloy milled for $200 \mathrm{~h}$ in argon and further milled under nitrogen. It transformed almost fully into a non-magnetic amorphous phase $\left(\mathrm{Fe}_{0.50} \mathrm{Cr}_{0.50}\right) \mathrm{N}_{0.058}$. [28]. Unfortunately, Shen et al. [26] did not determine the concentrations of $\mathrm{O}$ and $\mathrm{N}$ in their ballmilled samples. In any case, it would be difficult to explain the origin of significant concentrations of nitrogen (from one to some wt $\%[20-22,24,25])$ if the vial they used was air tight as reported. The main central Mössbauer peak, whose isomer shift is about $-0.1 \mathrm{~mm} / \mathrm{s}$, is attributed to 'disordered' $\mathrm{Fe}-\mathrm{Cr}+\mathrm{O}+\mathrm{N}$ grain boundaries $[21,22,25,26]$. In other words, the existence of the so-called 'disordered' $\mathrm{Fe}-\mathrm{Cr}+\mathrm{O}+\mathrm{N}$ regions produce large changes of the magnetic properties of the grain boundary regions as compared to those of $\mathrm{Fe}-\mathrm{Cr}$ alloys ball-milled under vacuum but such differences remain unexplained.

As discussed in previous sections, the formation of an amorphous phase at grain boundaries favoured by the presence of oxygen, or even that of an amorphous-bcc composite with amorphous layers surrounding bcc grains, appears to be a reasonable assumption both consistent with the X-ray diffraction pattern of a bcc phase and the change of magnetic properties. The assumption of the existence of an amorphous layer around grains is consistent too with the absence of a sigma phase in the annealed samples (Section 3.3). Indeed, the high density of grain boundaries accelerates the $\sigma$-phase precipitation when compared to the precipitation rate in a coarse-grained alloy ([8] for Fe-V alloys and [10] for $\mathrm{Fe}-\mathrm{Cr}$ alloys). A $\sigma$-phase fraction of $\sim 80 \%$ is found to form in mechanically alloyed nanocrystalline $\mathrm{Fe}_{0.555} \mathrm{Cr}_{0.445}$ by a short annealing of $10 \mathrm{~min}$ at $700{ }^{\circ} \mathrm{C}$ while it is negligible for the related coarse-grained alloy [10]. A strong slowing down of the precipitation rate is expected to occur when the nucleation sites of the sigma phase at grain boundaries are no more available ([10] for $\mathrm{Fe}-\mathrm{Cr}-\mathrm{Sn}$ alloys and references therein) as they would be in the presence of an amorphous interface.

At least two factors must be taken into account to explain the various results:

(1) the influence of residual gases (oxygen in our case);

(2) the influence of the injected power.

The strong influence of the injected power on the phenomenon of amorphization by ball-milling is indeed well-known and for instance clearly evidenced for $\mathrm{Ni}_{10} \mathrm{Zr}_{7}$ and for $\mathrm{Ni}_{3} \mathrm{Al}$ $[12,52,53]$. Domains with different proportions of amorphous and crystalline phases are found according to the injected power $[12,52,53]$. For near equiatomic $\mathrm{Fe}-\mathrm{Cr}$ alloys, the various experimental results suggest that amorphization favoured by oxygen would occur for samples milled at moderate injected powers (present work, [26]) while it would not at higher energy [28].

However, it would be premature to consider that a partial amorphization of such alloys would never occur in the absence of residual gases. The question of an intrinsic amorphization by ball-milling is all the more relevant that amorphous $\mathrm{Fe}-\mathrm{Cr}$ phases can be formed by other techniques in experimental conditions in which oxygen does not play a significant role [29,31]. In a dynamical equilibrium phase diagram of $\mathrm{Fe}-\mathrm{Cr}$ alloys milled under vacuum, the domain of amorphization is expected to be shifted downwards to smaller injected powers with respect to that of $\mathrm{Fe}-\mathrm{Cr}$ alloys milled in the presence of residual gases which stabilize the amorphous phase. This would explain why Shen et al. [26] did not observe an amorphous component in $\mathrm{Fe}_{0.60} \mathrm{Cr}_{0.40}$ milled in vacuum in a QM-1SP01 planetary mill with WC balls while its formation in the experiment of Bakker et al. [13,32,33] performed in vacuum with a P0 vibratory mill would explain the milling time dependence of the magnetization. Once formed from the sigma phase, the bcc phase is indeed expected to evolve as it would do in milling experiments performed from initial bcc phases.

An investigation of ball-milling in vacuum of elemental near-equiatomic $\mathrm{Fe}-\mathrm{Cr}$ powder mixtures (or grinding of as-cast alloys) as a function of the injected power is still needed before reaching a definite conclusion.

\section{Conclusions}

The sigma $\mathrm{FeCr}$ phase, either formed from as-cast or from nanocrystalline bcc alloys, is not stable during ball-milling as concluded earlier by Bakker et al. $[13,32,33]$ and its transforms into an alpha phase at a faster rate for the nanocrystalline $\sigma$-phase than for the coarse-grained phases. The formation of a ferromagnetic bcc phase is not the only phenomenon which occurs during milling in argon. Mössbauer spectroscopy shows further that a central non-magnetic component appears in our milling conditions. The associated phase, which remains non-magnetic down to $35 \mathrm{~K}$, has been argued to be an amorphous phase forming a layer around grains. A phase separation possibly occurs inside grains for longer milling times. We have attributed the diversity of experimental results on the final phases formed by milling of bcc near-equiatomic $\mathrm{Fe}-\mathrm{Cr}$ alloys to the influences of both residual gases and of injected power. Amorphization, favoured in our case by the presence of oxygen, enables us to explain the low saturation magnetization values of ball-milled alloys. A similar explanation may hold for the results of Bakker et al. $[14,32,33]$ even for alloys ball-milled in vacuum. The strong sensitivity of chemical order in near-equiatomic $\mathrm{Fe}-\mathrm{Cr}$ alloys to plastic deformation ([42] and references therein) might explain the dependence of final phases on the milling conditions. An investigation of ball-milling of near-equiatomic $\mathrm{Fe}-\mathrm{Cr}$ in vacuum in a broad range of injected power is still needed.

\section{Acknowledgements}

The authors wish to thank IFIMUP (Universidade do Porto) for the use of the SQUID, ICEMS (Universidade de Coimbra) for DSC measurements and Prof. S.M. Dubiel (AGH University of Science and Technology, Krakow, Poland) for useful comments and suggestions. The coarse-grained samples were prepared by Dr. Teresa Seixas of IMAT/IFIMUP (Universidade do Porto).

\section{References}

[1] F. Danoix, P. Auger, Mater. Charact. 44 (2000) 177-201.

[2] O. Kubachewski, Iron-Binary Phase Diagrams, Springer, Berlin, 1982, pp. 185. 
[3] S.M. Dubiel, G. Inden, Z. Metalkd. 78 (1987) 544-549.

[4] T. Ujihara, K. Osamura, Acta Mater. 48 (2000) 1629-1637.

[5] M. Honjo, Y. Sato, ISIJ Inst. 40 (2000) 914-919.

[6] M. Athenes, P. Bellon, G. Martin, Acta Mater. 48 (2000) 2675-2688.

[7] J.M. Roussel, P. Bellon, Phys. Rev. B 63 (2001) 184114 (15 pages).

[8] T. Ziller, G. Le Caër, O. Isnard, P. Cenedese, B. Fultz, Phys. Rev. B 65 (2002) 024204 (14 pages).

[9] P. Villars, L.D. Calvert, Pearsons's Handbook of Crystallographic Data for Intermetallic Phases, American Physical Society for Metals, Metals Park, OH, 1985, p. 2246.

[10] B.F.O. Costa, G. Le Caër, N. Ayres de Campos, Phys. Status Solidi (a) 183 (2001) 235-250.

[11] B.F.O. Costa, G. Le Caër, B. Luyssaert, J. Alloys Compd. 350 (2003) 36-46.

[12] G. Martin, P. Bellon, Solid State Phys. 50 (1996) 189-331.

[13] H. Bakker, G.F. Zhou, H. Yang, Progr. Mater. Sci. 39 (1995) 159-241.

[14] A.C. Lund, C. Schuh, Phys. Rev. Lett. 91 (2003) 235505 (4 pages).

[15] S. Odunuga, Y. Li, P. Krasnochtchekov, P. Bellon, R.S. Averback, Phys. Rev. Lett. 95 (2005) 045901 (4 pages).

[16] C. Suryanaryana, Progr. Mater. Sci. 46 (2001) 1-184.

[17] E. Gaffet, G. Le Caër, in: H.S. Nalwa (Ed.), Encyclopedia of Nanoscience and Nanotechnology, vol. 5, American Scientific Publishers, 2004, pp. 91-129.

[18] Y. Ivanisenko, I. MacLaren, R.Z. Valiev, H.J. Fecht, Adv. Eng. Mater. 7 (2005) 1011-1014.

[19] (a) P. Delcroix, T. Ziller, C. Bellouard, G. Le Caër, Mater. Sci. Forum 360-362 (2001) 329-336;

(b) G. Le Caër, S. Bégin-Colin, P. Delcroix, Material research in atomic scale by Mössbauer spectroscopy, in: M. Mashlan, M. Miglierini, P. Schaaf (Eds.), NATO Science Series II-Mathematics, Physics and Chemistry, vol. 94, Kluwer Academic Publishers, 2003, pp. 11-20.

[20] J. Rawers, R.C. Doan, G. Slavens, D. Govier, J. Siple, J. Mater. Synth. Process. 1 (1993) 75-84.

[21] J. Rawers, D. Govier, D. Cook, Scr. Metall. Mater. 32 (1993) 1319-1324.

[22] J. Rawers, D. Cook, T. Kim, Philos. Mag. A 78 (1998) 965-977.

[23] S.J. Campbell, W.A. Kaczmarek, in: G.J. Long, F. Grandjean (Eds.), Mössbauer Spectroscopy Applied to Magnetism and Materials Science, vol. 2, Plenum Press, New York, 1996, pp. 273-330 (in particular p. 306).

[24] C. Lemoine, A. Fnidiki, D. Lemarchand, J. Teillet, J. Phys.: Condens. Matter 11 (1999) 8341-8350.

[25] A. Fnidiki, C. Lemoine, J. Teillet, Phys. B 363 (2005) 271-281.

[26] G. Shen, D.M. Jiang, F. Lin, W.Z. Shi, X.M. Ma, Phys. B 367 (2005) 137-141.
[27] M.S. El-Eskandarany, K. Sumiyama, K. Aoki, K. Suzuki, Mater. Sci. Forum 88-90 (1992) 801-808.

[28] T. Koyano, T. Takizawa, T. Fukunaga, U. Mizutani, S. Kamizuru, E. Kita, A. Tasaki, J. Appl. Phys. 73 (1993) 429-433.

[29] S.K. Xia, E. Baggio-Saitovitch, F.C. Rizzo Assunçao, V.A. Pena Rodriguez, J. Phys.: Condens. Matter 5 (1993) 2729-2738.

[30] S.K. Xia, E. Baggio-Saitovitch, C. Larica, Phys. Rev. B 49 (1994) 927-931.

[31] A.A. Levin, D.C. Meyer, A. Gorbunov, A. Mensch, W. Pompe, P. Paufler, J. Alloys Compd. 360 (2003) 107-117.

[32] H. Yang, L.M. Di, H. Bakker, Intermetallics 1 (1993) 29-33.

[33] H. Yang, H. Bakker, Mater. Sci. Eng. A 181-182 (1994) 1207-1211.

[34] A.T. Aldred, Phys. Rev. B 14 (1976) 219-227.

[35] A.T. Aldred, B.D. Rainford, J.S. Kouvel, T.J. Hicks, Phys. Rev. B 14 (1976) 228-234.

[36] S. Meszaros, K. Vad, J. Hakl, L. Kerekes, P. Gurin, M. Kis-Varga, S. Szabo, D.L. Beke, P.F. de Chatel, Philos. Mag. B 81 (2001) 1597-1602.

[37] Z. Sefrioui, J.L. Menedez, E. Navarro, A. Cebollada, F. Briones, P. Crespo, A. Hernando, Phys. Rev. B 64 (2001) 224431 (4 pages).

[38] L. Del Bianco, A. Hernando, E. Bonetti, E. Navarro, Phys. Rev. B 56 (1997) 8894-8901.

[39] J. Balogh, T. Kemeny, I. Vincze, S. Szabo, D.L. Beke, J. Toth, Phys. Rev. B 59 (1999) 14786-14787.

[40] L. Del Bianco, A. Hernando, E. Bonetti, C. Ballesteros, Phys. Rev. B 59 (1999) 14788-14789.

[41] J. Balogh, L. Bujdoso, D. Kaptas, T. Kemeny, I. Vincze, S. Szabo, D.L. Beke, Phys. Rev. B 61 (2000) 4109-4116.

[42] P. Delcroix, G. Le Caër, B.F.O. Costa, ISMANAM 2005, Paris, 4-7 July 2005. J. Alloys Compd., in press.

[43] G. Williamson, W.H. Hall, Acta Metall. 1 (1952) 22-31.

[44] G. Le Caër, J.M. Dubois, J. Phys. E 12 (1979) 1083-1090.

[45] D. Chandra, L.H. Schwartz, Met. Trans. 2 (1971) 511-519.

[46] R. Deschamps, P.M. Gielen, Membr. Sci. Rev. Metall. (1976 Septem) 537-551.

[47] S.M. Dubiel, J. Zukrowski, J. Magn. Magn. Mater. 23 (1981) 214-228.

[48] H. Kuwano, K. Ono, J. Phys. Soc. Jpn. 42 (1977) 72-75.

[49] J. Cieslak, S.M. Dubiel, B. Sepiol, J. Phys.: Condens. Matter 12 (2000) 6709-6717.

[50] E. Le Bourhis, P. Goudeau, J.P. Eymery, W. Al-Khoury, Eur. Phys. J. Appl. Phys. 30 (2005) 33-39.

[51] G.J. Fan, H. Choo, P.K. Liaw, E.J. Lavernia, Mater. Sci. Eng. A 409 (2005) 243-248.

[52] M. Abdellaoui, E. Gaffet, J. Alloys Compd. 209 (1994) 351-361.

[53] E. Gaffet, Mater. Sci. Forum 225-227 (1996) 429-434. 